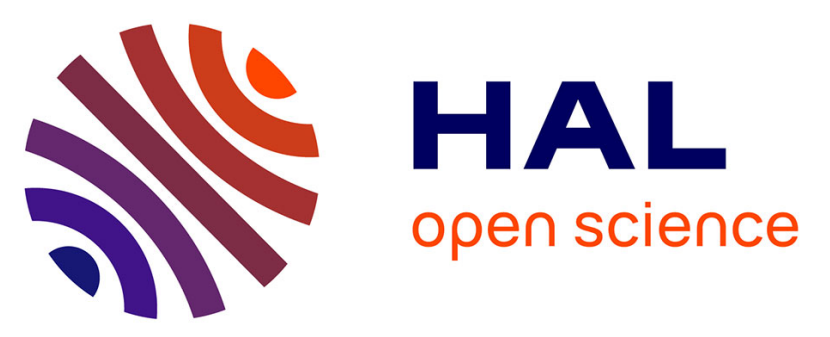

\title{
Coupling deterministic and random sequential approaches for structure and texture prediction of a dairy oil-in-water emulsion
}

Etienne Descamps, Nathalie Perrot, Ioan-Cristian Trelea, Sebastien Gaucel, Alain Riaublanc, Alan Mackie, Evelyne Lutton

\section{To cite this version:}

Etienne Descamps, Nathalie Perrot, Ioan-Cristian Trelea, Sebastien Gaucel, Alain Riaublanc, et al.. Coupling deterministic and random sequential approaches for structure and texture prediction of a dairy oil-in-water emulsion. Innovative Food Science \& Emerging Technologies / Innovative Food Science and Emerging Technologies , 2014, 25, pp.28-39. 10.1016/j.ifset.2013.12.003 . hal-01195497

\section{HAL Id: hal-01195497 \\ https://hal.science/hal-01195497}

Submitted on 11 Jul 2017

HAL is a multi-disciplinary open access archive for the deposit and dissemination of scientific research documents, whether they are published or not. The documents may come from teaching and research institutions in France or abroad, or from public or private research centers.
L'archive ouverte pluridisciplinaire HAL, est destinée au dépôt et à la diffusion de documents scientifiques de niveau recherche, publiés ou non, émanant des établissements d'enseignement et de recherche français ou étrangers, des laboratoires publics ou privés. 


\title{
Coupling deterministic and random sequential approaches for structure and texture prediction of a dairy oil-in-water emulsion
}

\author{
Etienne Descamps ${ }^{1}$, Nathalie Perrot ${ }^{1}$, Ioan Cristian Trelea ${ }^{1}$, Sebastien Gaucel ${ }^{1}$, Alain Riaublanc ${ }^{2}$, Alan \\ Mackie $^{3}$, Evelyne Lutton ${ }^{1}$ \\ a INRA/AgroParisTech, UMR782 Génie et Microbiologie des Procédés Alimentaires, F-78850 Thiverval-Grignon, France \\ ${ }^{b}$ UR 1268 Biopolymères, Interactions, Assemblages, INRA, rue de la Géraudière 44316 Nantes, France \\ ${ }^{c}$ Institute of Food Research, Norwich Research Park Colney, Norwich NR4 7UA, UK
}

\begin{abstract}
Dairy products made of concentrated milk protein powder and milk fat have been experimentally shown to behave like complex systems: The resulting textures depend on various factors, including concentration and type of proteins, nature of heat treatment and homogenisation process. The aim of this paper is to combine two models in order to predict the composition of the interface of an homogenised oil-in-water emulsion, and the resulting bridge structure between the fat droplets. This structure is then correlated to the texture of the emulsion.

Free unknown parameters of both models have been estimated from experimental data using an evolutionary optimisation algorithm. The resulting model fits the experimental data, and is coherent with the macroscopic texture measurements.
\end{abstract}

Keywords: milk gel model, dairy products, oil-water interface, non linear optimisation, model coupling, knowledge integration

\section{Introduction}

Surface-active molecules, such as proteins, polymers, ionic and non-ionic surfactants play a major role in the stabilisation of dispersed system such as oil in water emulsions [1]. In food systems, an important class of emulsifiers are proteins: they are adsorbed on the oil droplet surface during homogenisation. Stabilisation is a consequence of the ability of the proteins to generate repulsive interactions (steric and electrostatic) between oil droplets [2].

The emulsifying properties of milk proteins are excellent and justify their wide use in food processing [3]. Milk proteins are divided in two major categories: caseins (as casein micelles (CM) or individual caseins) and native whey proteins (WP).

During most of milk gels processing, the milk proteins solution undergoes a heat treatment. Usually, a heat treatment denatures soluble proteins and aggregates of proteins appear, with a strong impact on the physicochemical properties of the final product. Above $70^{\circ} \mathrm{C}$, whey proteins are partly denatured and form

Email addresses: etienne.descamps@grignon.inra.fr (Etienne Descamps ${ }^{1}$ ), nathalie.perrot@grignon.inra.fr (Nathalie Perrot ${ }^{1}$ ), cristian.trelea@agroparistech. fr (Ioan Cristian Trelea ${ }^{1}$ ), sebastien.gaucel@grignon.inra.fr (Sebastien Gaucel ${ }^{1}$ ), alain.riaublanc@nantes.inra.fr (Alain Riaublanc ${ }^{2}$ ), alan.mackie@bbsrc.ac.uk (Alan Mackie ${ }^{3}$ ), evelyne.lutton@grignon.inra.fr (Evelyne Lutton ${ }^{1}$ ) 
aggregates (WPA) while casein micelles are less sensitive to heat treatment but can form complexes with WP (CMWP). This last reaction is in competition with the whey proteins aggregation [4]. All these phenomena lead to four potential types of proteins in the solution: (CM), (WP), (WPA) and (CMWP).

Several studies on milk gels [1, 5, 6, 7, 8] showed the importance of the dynamics and competition between these types of particles taking place at a fluid-fluid interface of lipid droplets during the emulsion. Although studies describe the structuring of pure whey protein aggregates (WPA) submitted to heat [9]. Nevertheless less is known about the behaviour of complex aggregates made of casein micelles and whey proteins (CMWP) [10]. Moreover, the data and expertise collected on complex aggregates is generally difficult to integrate in existing models [11]. Mixed solutions are not thermodynamically controlled processes of competitive adsorption, and cannot be predicted from any classical model like the Langmuir one [9, 3]. In this context, stochastic approaches simulating the layer of adsorbed protein at the nanooscopic level are relevant, but need important computing time if several types of particles are considered. The surface-active molecules, i.e. the CMWP aggregates, are in competition with the pure whey protein (WPA) aggregates at the oil in water interface and play a major role in the network created at a higher level. As highlighted by Dickinson [8], the interpretation of surface composition in emulsion containing the full range of aggregated milk proteins is quite complex and certainly not yet fully understood. Modelling is a good candidate to help to understand such systems.

Experiments have been previously performed, generating complex unexpected behaviour, for a same total concentration of proteins, when using different mass ratio of $(\mathrm{CM})$. A wide range of interfacial composition have been generated when changing this initial condition. The work presented in this paper starts from those observations.

We propose a computational approach to simulate the structure of a dairy emulsion, from a given composition and process condition. The computational approach is validated on the available dataset. The model uses a stochastic approach to generate at the nanoscopic scale a random spatial configuration of the physical elements of the emulsion. The purpose of the model is to predict the emergence of the macroscopic structure from the local organisation at the nanoscopic scale. This approach is strongly inspired by the Random Sequential Adsorption (RSA) model [12] and its derivatives [13], with the particularity that the interface is not represented as a plane, but as a 3D surface made of randomly distributed fat droplets in the space.

Additionally, our model is able to manage the competition of elements of different sizes, which is not considered in previous RSA models.

The paper is organised as follows. After a description of the experimental data used to optimise and validate the model (section 2), the model is developed in section 3 Results are presented in section 4 , after a sensitivity analysis, the parameters of the model are fitted using an evolutionary optimisation approach (CMA-ES) [14]. Discussion, conclusions and future work are finally developed in sections 5 and 6

\section{Experimental data}

Various emulsions were generated with a range of controlled interfacial compositions (weight ratio of casein micelles (CM) to whey proteins (WP) from 80:20 to 12:88). Two sets of experiments were made:

- To build the model, a first database was collected from experiments conducted at the pilot plant of INRA BIA (Institut National de Recherche Agronomique, Biopolymères - Interactions - Assemblages, Nantes, France) [15].

- To validate the model, a second database was collected from experiments conducted in the laboratory of IFR (Institute of Food Research, Norwich, England) [16]. 


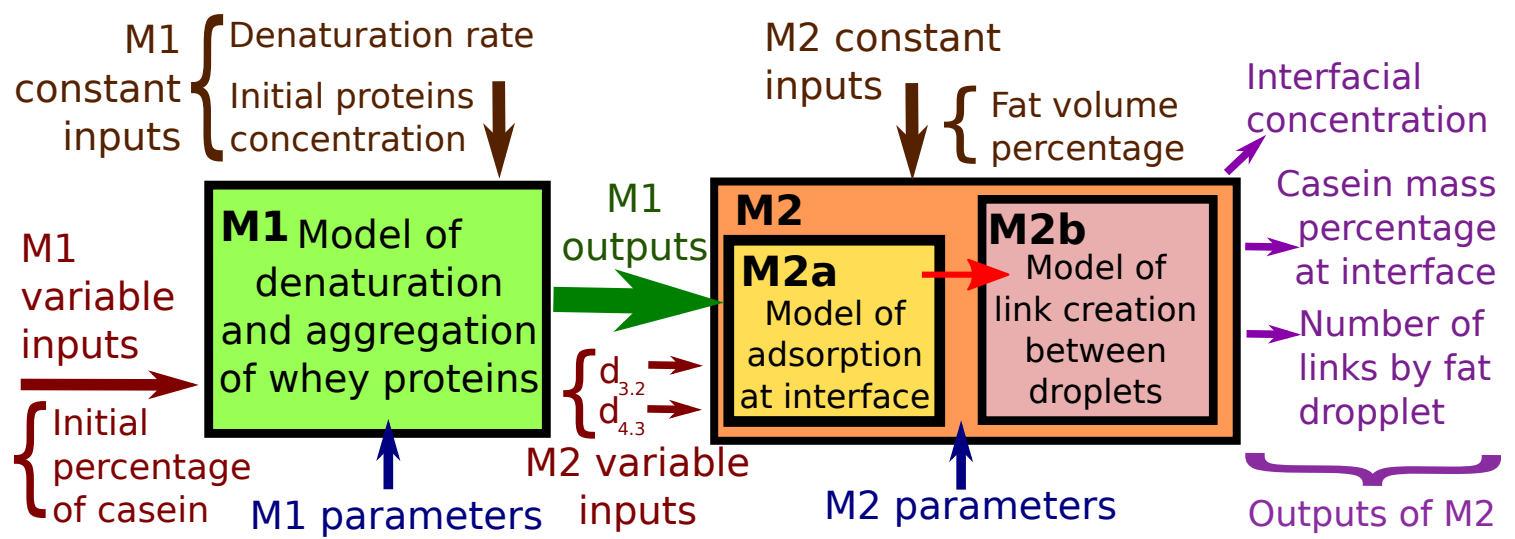

Figure 1: Input and parameters of both models M1 and M2

Both sets of experiments were made with the same preheat treatment and protein solutions, but with different experimental devices and volumes. The protein phases of both experimental datasets were made of the same powders, with the same ionic strength, $\mathrm{pH}$ and ion composition.

The two emulsion processes were based on the same principle: the continuous phase of the emulsion was formed from milk proteins dissolved in permeate. These milk proteins were a mixture of caseins (Promilk 852B, IDI company, France with 5\% moisture, $1.5 \%$ fat, $85.5 \%$ nitrogenous matter/dry matter, $8.5 \%$ mineral matter, $4 \%$ lactose, $81 \%$ nitrogenous matter (on powder), $92 \%$ casein micelle, $2.6 \% \mathrm{Ca}, 1.5 \% \mathrm{P}, 0.3 \% \mathrm{~K}$, $0.1 \% \mathrm{Na}$ and $0.1 \%$ of $\mathrm{Mg}$ ) and native whey proteins (BiPro, DAVISCO company, Minnesota with $5 \%$ max of moisture, $95 \%$ min. of protein, dry basis, $1 \%$ max fat, $3 \%$ max ash, $1 \%$ max lactose, a pH between 6.7 and 7.5) with milk permeate powder (Armor protéines, France with a pH of $6.0 \mathrm{~min}, 3 \%$ max moisture, 3\% min proteins, $1 \%$ max fat, $82 \%$ lactose, $8 \%$ ashes). The continuous phase was prepared the day before use, was stored at $4^{\circ} \mathrm{C}$ and then heated at $80^{\circ} \mathrm{C}$. The dispersed phase of the emulsion is made of saturated lipid: anhydrous milk fat (AMF) heated at $60^{\circ} \mathrm{C}$ to become liquid. These two phases were then homogenised in order to get an emulsion.

The processes are different for the homogenisation and volume of resulting emulsion. For Database 1, the blending was done with a rotor stator (Polytron, Heidolph Silent Crusher M), in a low pressure homogeniser (Stansted Fluid Power, Stansted, UK) at 50 bars, whereas experiments in Database 2 were made with a blender (BL450 series, KENWOOD) with a shearing cycle (30 seconds low speed, 30 seconds of rest, then 2 x 30 seconds high speed) and in a manual homogeniser (EmulsiFlex - B3, AVESTIN) using 6 passes at 20 $\mathrm{x} 200$ PSI.

In Database 1, the emulsion mass was $70 \mathrm{~g}$ ( $49 \mathrm{~g}$ of continuous phase and $21 \mathrm{~g}$ of dispersed phase) and in Database 2, the emulsion mass was $260 \mathrm{~g}$ (182 $\mathrm{g}$ of continuous phase and $78 \mathrm{~g}$ of dispersed phase).

In order to evaluate the impact of initial conditions on the structure and texture of the emulsion, experiments were carried out with various initial conditions (Table 1). The following initial conditions were kept the same for every experiment:

- For Database 1: the pre-heat treatment temperature of milk proteins was $80^{\circ} \mathrm{C}$, the denaturation level, i.e. the proportion of denatured WP in the solution, was around 0.6 and the mass of lipid was $21 \mathrm{~g}$, for a total emulsion volume of $70 \mathrm{~mL}$.

- For Database 2, the pre-heat treatment temperature of milk proteins was $80^{\circ} \mathrm{C}$ and the mass of lipid 
Table 1: Initial conditions and measurement results for Databases 1 and 2.

$d_{3.2}$ : Surface area mean diameter of fat droplets,

$d_{4.3}$ : Volume mean diameter,

$w_{c m_{0}}$ : Initial percentage of caseins in the solution,

$w_{c m_{a d s}}$ : Percentage of adsorbed caseins,

$c_{\text {prot }}$ : Protein concentration in water phase.

$\Gamma$ : Interfacial concentration.

\begin{tabular}{|c|c|c|c|c|c|}
\hline $\begin{array}{c}w_{\text {cas }_{0}} \\
(\%)\end{array}$ & $\begin{array}{c}\mathbf{d 3 . 2} \\
(\mu \mathrm{m})\end{array}$ & $\begin{array}{c}\mathbf{d 4 . 3} \\
(\mu \mathrm{m})\end{array}$ & $\begin{array}{c}c_{\text {prot }} \\
\left(\mathrm{g} . \mathrm{L}^{-1}\right)\end{array}$ & $\begin{array}{c}w_{\text {cas }}(\%) \\
(\%)\end{array}$ & $\begin{array}{c}\Gamma \\
\left(\mathrm{mg} . \mathrm{m}^{-2}\right)\end{array}$ \\
\hline \multicolumn{6}{|c|}{ Database 1 } \\
\hline \hline 13 & 0.5 & 0.8 & 48.4 & 9 & 7.1 \\
\hline 19 & 0.45 & 0.7 & 48.8 & 13 & 4.4 \\
\hline 21 & 0.5 & 0.8 & 48.9 & 22 & 3.9 \\
\hline 26 & 0.4 & 0.7 & 48.9 & 41 & 3.4 \\
\hline 32 & 0.45 & 1.1 & 49.4 & 68 & 5.7 \\
\hline 49 & 0.57 & 0.9 & 49.7 & 61 & 7.2 \\
\hline 80 & 0.8 & 1.0 & 50.4 & 83 & 6.1 \\
\hline \hline \multicolumn{7}{|c|}{ Database 2} \\
\hline \hline 13 & 0.76 & 1.19 & 48.3 & 0 & 7.79 \\
\hline 31 & 0.94 & 1.55 & 47.5 & 4 & 5.48 \\
\hline 49 & 0.94 & 1.60 & 49.7 & 54 & 8.04 \\
\hline 80 & 0.86 & 1.43 & 50.4 & 80 & 7.22 \\
\hline
\end{tabular}


was $78 \mathrm{~g}$, for a total emulsion volume of $260 \mathrm{~mL}$.

The following measurements were collected for characterising the emulsions at a micro/nanoscale.

- Diameter and size distribution of lipid droplets. Laser light scattering was used to measure the diameter of the lipid droplets in the emulsion and evaluate the size distribution. In Database 1, measurements were made using a Saturn DigiSizer 5200 (Micromeritics, Norcross, USA). These measurements enabled us to calculate the initial free lipid surface $S_{0}$. In Database 2, measurements were made using an LS 13320 Laser Diffraction Particle Size Analyser (Beckman Coulter). The measurement error for all considered devices is around $10 \%$.

- Diameter and size distribution of whey protein aggregates. Dynamic light scattering was used to measure the diameter of the whey protein aggregates in the emulsion and evaluate the size distribution. In Databases 1 and 2, these measurements were made using a Nanosizer ZS (Malvern Instrument, UK).

- Interfacial concentration $(\Gamma)$ and percentage of adsorbed caseins $\left(w_{\text {cas ads }}\right)$. In Database 1 , the study of the composition of the interface of lipid droplets was carried out with the Patton and Huston technique [17] which is used to separate droplets. The protein concentration at the interface was then quantified by the Markwell method [18]. SDS-PAGE electrophoresis was then used to determine the concentration of each protein at the interface. In Database 2, SDS-PAGE electrophoresis was carried out and gels were purchased from Invitrogen Ltd. (Paisley, UK).

The measurement error of the Patton techniques and electrophoresis were each around 10\%.

- Sensory measurements. Two groups of sensory texture were described during experiments for each conditions: gelified or liquid. Measurements were performed [19] on the emulsion 2 hours after the processing at $20^{\circ}$ and confirmed by two techniques (1) a controlled stress rheometer (AR 2000, TA Instruments, New Castle, Delaware, USA) using plate-plate geometry (diameter $60 \mathrm{~mm}$, gap 100 $\mu \mathrm{m}$ ) for Database 1 and a cone-plate geometry (cone diameter $40 \mathrm{~mm}$, gap $62 \mu \mathrm{m}$ ) for Database 2 . (2) Viscoelastic measurements performed with a controlled stain rheometer (ARES, TA Instruments, New Castle, Delaware, USA) using a plate-plate geometry (diameter $40 \mathrm{~mm}$, gap $100 \mu \mathrm{m}$ ) at $20^{\circ} \mathrm{C}$. A dynamic mechanical spectrum $\left(\mathrm{G}^{\prime}\right.$, storage modulus and $\mathrm{G}^{\prime}$, , loss modulus as a function of the angular frequency) was obtained in a frequency range of frequency from 0.01 to $100 \mathrm{rad} / \mathrm{s}$, at $10 \%$ shear strain.

\section{Coupled models for a milk gel emulsion}

The model presented in this paper is a coupling between a first order differential kinetic model of protein denaturation (M1) and a stochastic model of simulation of the fat droplets interface colonisation (M2a) and bridge creation between fat droplets (M2b) (Figure 1). Coupling M1 and M2 allows to simulate the emergence of a network at a mesoscale level from local droplet considerations. Both models are presented below.

\subsection{M1: First order differential kinetic model of protein denaturation}

The first model aims at simulating the denaturation process, in particular the competitive reaction that occurs during the thermal denaturation of whey proteins. According to the values of the parameters of M1, denatured WP are more or less associated with CM or aggregated in the form of WPA. The outputs of M1 are the mass concentration of WPAs and the mass concentration of CMWPs. The assumptions are the following: 
Table 2: Model M1 Glossary

\begin{tabular}{|c|c|c|}
\hline Name & Description & Unit \\
\hline \multicolumn{3}{|c|}{ Parameters } \\
\hline$k_{d}$ & Denaturation rate of native WP & $\mathrm{m}^{1.5} \cdot \mathrm{g}^{-0.5} \cdot \mathrm{s}^{-1}$ \\
\hline$k_{\mathrm{ag}}$ & Aggregation rate of denatured WP & $\mathrm{m}^{1.5} \cdot \mathrm{g}^{-0.5} \cdot \mathrm{s}^{-1}$ \\
\hline$k_{\mathrm{cm}}$ & Association rate between denatured WP and CM & $\mathrm{m}^{3} \cdot \mathrm{g}^{-1} \cdot \mathrm{s}^{-1}$ \\
\hline \multicolumn{3}{|c|}{ Inputs } \\
\hline$\eta$ & Denaturation level of WP & $\%$ \\
\hline$\rho_{\mathrm{wp}}(0)+\rho_{\mathrm{cm}}$ & Initial proteins mass concentration & g. $\mathrm{m}^{-3}$ \\
\hline$w_{\mathrm{cm}_{0}}$ & Initial mass percentage of casein & $\%$ \\
\hline \multicolumn{3}{|c|}{ State variables } \\
\hline$\rho_{\mathrm{cm}}$ & CM mass concentration & g.m $\mathrm{m}^{-3}$ \\
\hline$\rho_{\mathrm{wpcm}}$ & Mass concentration of WP associated with CM & g. $\mathrm{m}^{-3}$ \\
\hline$\rho_{\mathrm{wpa}}$ & WP aggregates mass concentration & g. $\mathrm{m}^{-3}$ \\
\hline$\rho_{\mathrm{wp}}$ & WP natives mass concentration & g.m $\mathrm{m}^{-3}$ \\
\hline$\rho_{\mathrm{wp} *}$ & Free denatured WP mass concentration & g. $\mathrm{m}^{-3}$ \\
\hline \multicolumn{3}{|c|}{ Outputs of the model } \\
\hline$\frac{\rho_{\mathrm{wpcm}}(\infty)}{\rho_{\mathrm{wp}}(0)}$ & Ratio of denatured WP that associates with CM & \\
\hline
\end{tabular}

- According to [20], the denaturation reaction of the $\beta$-lactoglobulin is a kinetic reaction of order 1.5(equation 11]. This reaction is known as following an Arrhenius law (equation 2] [21]. All native whey proteins are supposed to have the same kinetic as $\beta$-lactoglobulin.

- The reactions of aggregation and denaturation have the same order of 1.5. The two reactions are merged in one [22] (equation 3].

- The association step is a first order reaction with respect to the concentrations of casein micelle and denatured whey protein that are not yet aggregated. A denatured WP can join either the surface of a CM or a WPA. The affinity of association between WPs and CM is considered as constant. The possible association between an aggregate and casein micelles is neglected (equation 47).

- The simulated process is simplified: the temperature is considered constant along the heat treatment; denaturation is supposed to stop when the experimental measured denaturation rate is reached.

The full model is then made of a set of three differential equations (Figure 2):

- The denaturation reaction given by [20]:

$$
\frac{d \rho_{\mathrm{wp}} *}{d t}=k_{d}(T) \times\left(\rho_{\mathrm{wp}}\right)^{1.5}
$$

$k_{d}(T)$ follows an Arrhenius law according to temperature with known parameters [21]:

$$
k_{d}(T)=k_{d_{0}} \exp \left\{-E_{a_{d}} / R T\right\}
$$

In our experiments, $T$ is fixed to $80^{\circ} \mathrm{C}, k_{d}$ is also fixed until the experimental denaturation rate is reached. 


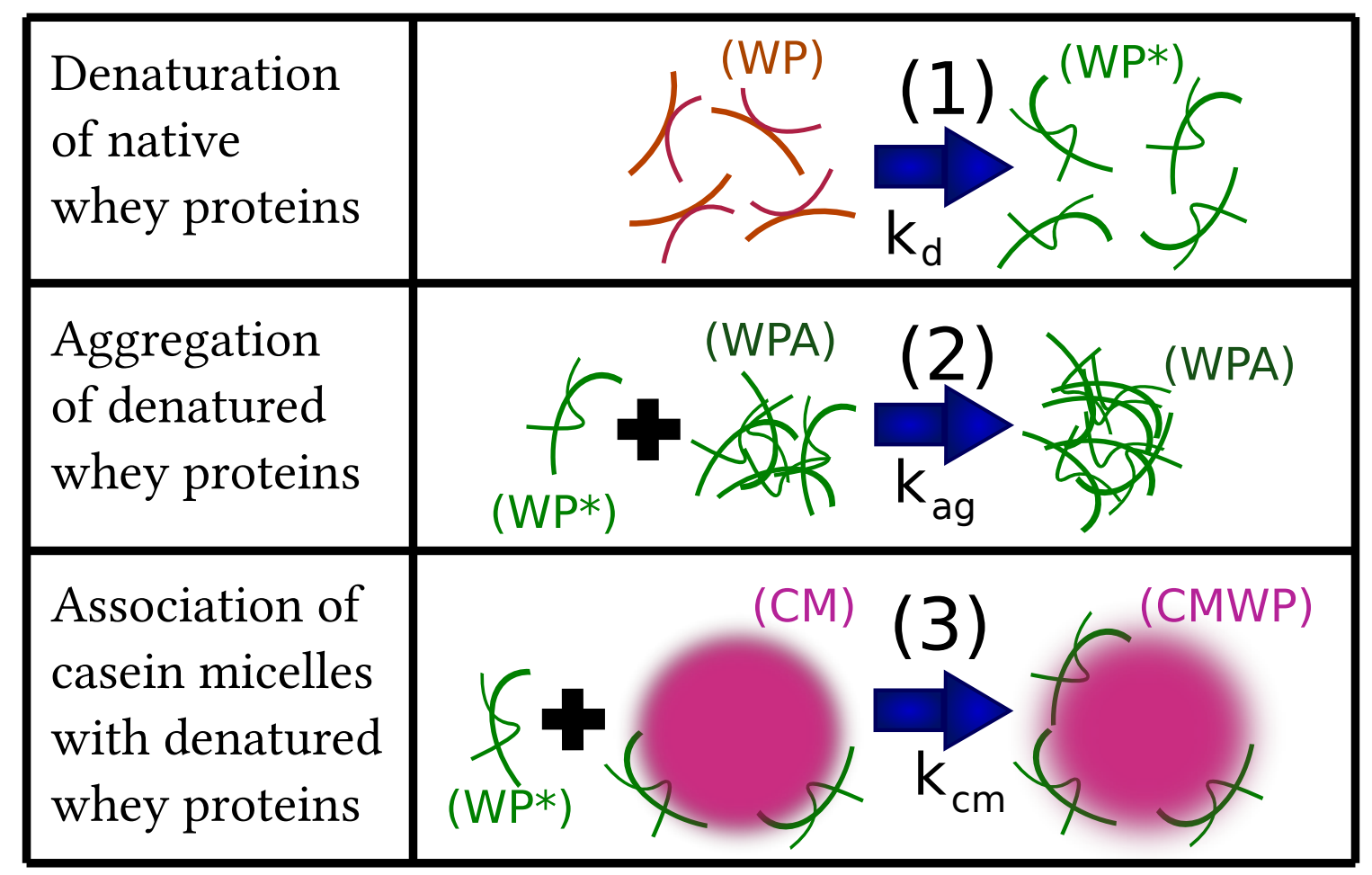

Figure 2: The three steps of a denaturation reaction. 

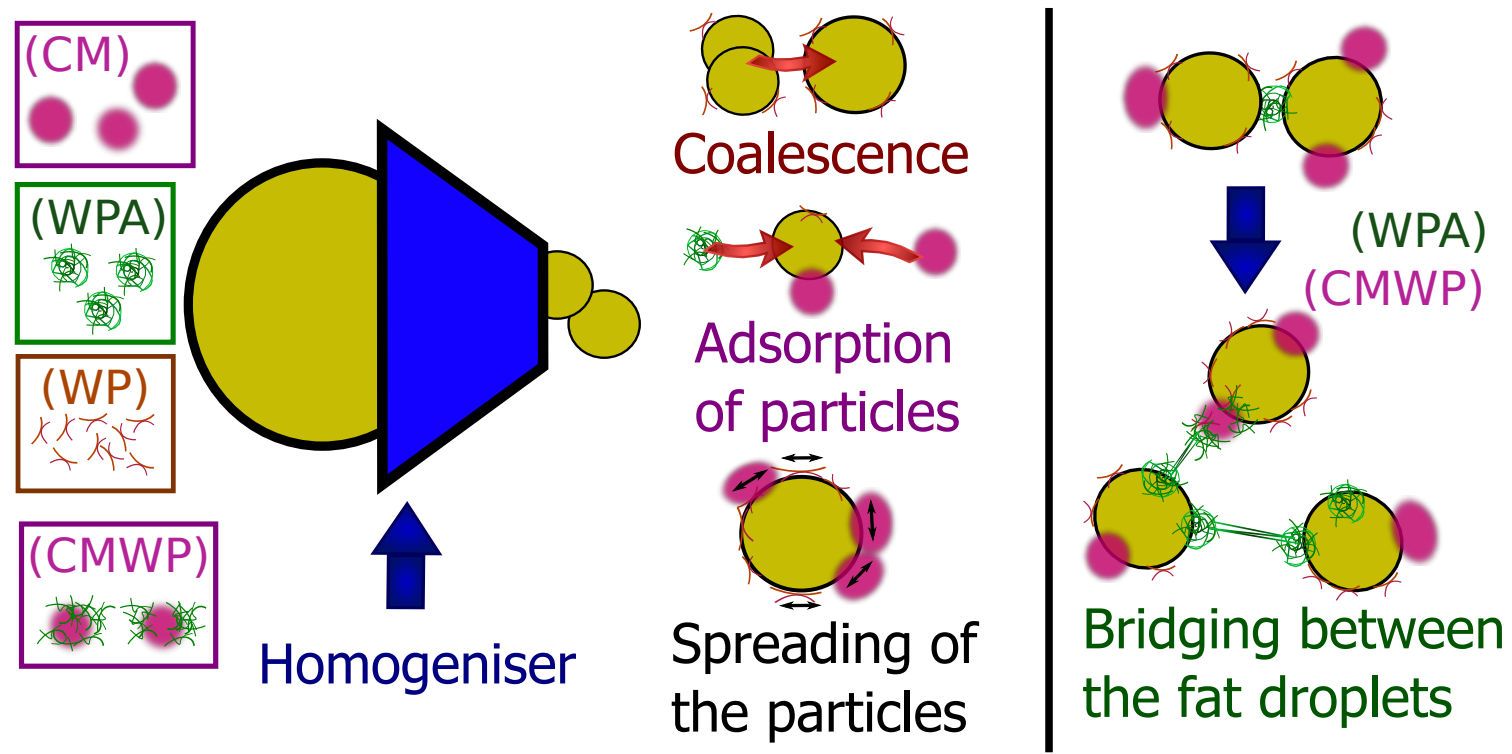

Figure 3: Coalescence and adsorption at the exit of the homogeniser

- For the aggregation reaction, a similar law is used with an order of reaction of 1.5 [20, 22]:

$$
\frac{d \rho_{\mathrm{wpa}}}{d t}(t)=k_{\mathrm{ag}} \rho_{\mathrm{wp}}{ }_{\mathrm{wp}}
$$

- The association between casein micelles and non aggregated denatured whey proteins is modelled using a linear dependant law:

$$
\frac{d \rho_{\mathrm{wpcm}}}{d t}(t)=k_{\mathrm{cm}} \rho_{\mathrm{cm}} \rho_{\mathrm{wp}}(t)
$$

In this model, $k_{d}$ is used as a reference for the other reactions, $k_{\mathrm{ag}}$ and $k_{\mathrm{cm}}$, and fixed to 1 . Indeed, only equilibrium values predicted by M1 are used by M2, which allows to fix one of the reaction constants arbitrarily.

\subsection{M2: Adsorption at interface and bridging between fat droplets \\ 3.2.1. Model structure}

The model is based on a three dimensional space representation. This 3D space is a cube representing a random distribution of the fat droplets. It has been calibrated using $d_{3,2}$ and $d_{4,3}$, measured for each experiments (Table 1 ) as explained in section 3.2 .2 below. For the adsorption process, a competition between WPA, WP and CM (including CMWP) is considered. This competition depends on the current interfacial concentration of adsorbed native WP at the surface of the droplets.

The model is made of two compartments (Figure 11). The first compartment simulates the adsorption and gives the final interface configuration at the local level of each fat droplet (M2a in Figure 1). The second compartment uses the space configuration to estimate the ability of each adsorbed element to link with another fat droplet (M2b in Figure 1).

A stochastic approach using Brownian dynamics is used to determine the potential of bridging between fat droplets (M2b). 
Table 3: Model M2 Glossary

\begin{tabular}{|c|c|c|}
\hline Name & Description & Unit \\
\hline \multicolumn{3}{|c|}{ Constants } \\
\hline$S_{\mathrm{wpa}}$ & WPA radius & $\mathrm{nm}$ \\
\hline$s_{\mathrm{wp}}$ & Native WP radius & $\mathrm{nm}$ \\
\hline$m_{\mathrm{wp}}$ & Native WP mass & $\mathrm{g}$ \\
\hline$s_{\mathrm{cm}}$ & $\mathrm{CM}$ radius & $\mathrm{nm}$ \\
\hline$m_{\mathrm{cm}}$ & CM mass & g \\
\hline$D_{\text {wpa }}$ & Fractal dimension of the WPAs & * \\
\hline \multicolumn{3}{|c|}{ Parameters of M2a } \\
\hline$r_{0}$ & Radius of the fat droplets at the exit of the homogeniser & $\overline{\mathrm{nm}}$ \\
\hline $\mathrm{Ksp}_{\mathrm{cm}}$ & Maximal spreading of CM & * \\
\hline $\mathrm{Ksp}_{\mathrm{wpa}}$ & Maximal spreading of WP aggregates & * \\
\hline$\Gamma_{\mathrm{wp}}$ & Maximal concentration of a one layer native WP interface & $m g \cdot m^{-2}$ \\
\hline $\mathrm{F}_{\mathrm{cm}}$ & Adsorption rate of CM (including CMWP) & * \\
\hline $\mathrm{F}_{\mathrm{wp}}$ & Adsorption rate of natives WP & * \\
\hline $\mathrm{F}_{\mathrm{wpa}}$ & Adsorption rate of WP aggregates & * \\
\hline \multicolumn{3}{|c|}{ Parameters of M2b } \\
\hline$\overline{\mathrm{K}_{\text {lnk }_{\mathrm{wpa}}}}$ & Link factor of WP aggregates & * \\
\hline $\mathrm{K}_{\text {lnk }_{\text {cmwp }}}$ & Link factor of activated CM & * \\
\hline$\mu_{\mathrm{cmwp}}$ & WP mass activation threshold of a CM & $g \cdot g^{-1}$ \\
\hline$\gamma_{\mathrm{cmwp}}$ & Variance of WP association on CM & $g \cdot g^{-1}$ \\
\hline \multicolumn{3}{|c|}{ Inputs } \\
\hline $\bar{V}$ & Volume of the space simulated by the model & $m^{3}$ \\
\hline$N_{\mathrm{cm}}$ & Number of CM & * \\
\hline$N_{\text {wpa }}$ & Number of WP aggregates & * \\
\hline$N_{\text {wp }}$ & Number of natives WP & * \\
\hline$\left\{\left(G_{i}\right)_{1}^{k}\right\}$ & Fat droplets population present in the space & \\
\hline$m_{\mathrm{cmwp}}$ & Mass mean of WP associated on CM & $g \cdot g^{-1}$ \\
\hline \multicolumn{3}{|c|}{ State variables } \\
\hline$\left\{\left(P_{i}\right)_{1}^{p}\right\}$ & $\begin{array}{l}\text { Set of adsorbed elements including type and possible geometric } \\
\text { information }\end{array}$ & \\
\hline$\left\{\left(L_{i}\right)_{1}^{q}\right\}$ & Set of links between particles and fat droplets & \\
\hline \multicolumn{3}{|c|}{ Outputs of the model } \\
\hline$\Gamma$ & Interfacial concentration & $\mathrm{mg} \cdot \mathrm{m}^{-2}$ \\
\hline$w_{\mathrm{cm}}$ ads & Mass percentage of casein adsorbed at the interface & $\%$ \\
\hline$G_{\text {link }}$ & Average number of links by droplet & $*$ \\
\hline$p_{\text {lnk }_{\text {CMWP }}}$ & Percentage of CMWP in the links set & $\%$ \\
\hline
\end{tabular}

(*) dimensionless. 


\subsubsection{Implementation of the adsorption model (M2a)}

The following assumptions have been made, in order to reduce the unknown parameter space and the complexity of the model:

- $A_{1}$ : The desorption phenomenon is neglected. The adsorption of the WP and of some casein proteins are known to be irreversible [23]. As a consequence, we consider the WP aggregation and MC adsorption as irreversible too.

- $A_{2}$ : The native WPs can move on the interface [24]. To take into account this phenomenon, the model processes the native WPs in a different way than the other particles. Indeed, it only takes into account the surface occupied by all adsorbed native WPs, and does not allocate them a fixed position at interface. All further adsorbed elements are supposed to be able to push the whey proteins on the interface. WPs are managed as a population contrarily to the other particles in competition (WPA, CM and CMWP), where interaction between individuals is taken into account. A droplet only contains the information of the mass of native WPs adsorbed at its surface. Due to the high concentration of ionic elements present in the solution, the electrostatic repulsion is neglected.

- $A_{3}$ : The coalescence phenomenon is simplified, and obeys to an inverse exponential law. The homogeniser is supposed to generate an initial population of fat droplets with a mean radius of $100 \mathrm{~nm}$. This population then converges to a distribution that corresponds to the experimental values of $d_{4,3}$ and $d_{3,2}$. Coalescence is represented by a mean field law.

- $A_{4}$ : The size of the aggregates of whey proteins has been measured during the experiments : it is considered as fixed with radius $s_{\mathrm{wpa}}=65 \mathrm{~nm}$ in the given conditions [15]. It has been reported that the fractal dimension of these aggregates is $D_{\text {wpa }}=2.4$ [25] and that the size of a native whey protein is around $s_{\mathrm{wp}}=1.5 \mathrm{~nm}[26$, which allows to compute the weight of each aggregate (equation 9).

- $A_{5}$ : The size of casein micelles have also been measured with a size of $s_{\mathrm{cm}}=75 \mathrm{~nm}$ and a mass of $m_{\mathrm{cm}}=5.77 \cdot 10^{-16} \mathrm{~g}$.

- $A_{6}$ : Spreading is a deformation of the particle at the surface of the fat droplet after adsorption. It is modeled as an instantaneous phenomenon whose caracteristic parameter is the increase factor of the apparent radius of the particle.

The model M2 simulates a fraction of volume $V$ of the emulsion. Inside this volume, a population of fat droplets is placed. The droplets sizes are randomly generated using the experimental measures (distribution of fat droplets and fat volume fraction). The size distribution is defined with two parameters, $d_{4,3}$ and $d_{3,2}$ :

$$
d_{4,3}=\frac{\sum_{i} d_{i}^{4}}{\sum_{i} d_{i}^{3}} ; d_{3,2}=\frac{\sum_{i} d_{i}^{3}}{\sum_{i} d_{i}^{2}}
$$

The parameters of a log normal distribution are straighforwardly calculated from these two factors. Suppose the diameter distribution follows a $\ln \mathcal{N}\left(\mu, \sigma^{2}\right)$ law, $d^{k}$ then follows a $\log$ normal law $\ln \mathcal{N}\left(k \cdot \mu, k^{2}\right.$. $\left.\sigma^{2}\right) . d_{4,3}$ and $d_{3,2}$ are determined from the mean values of the log normal distribution $e^{\mu+\frac{\sigma^{2}}{2}}$ :

$$
\begin{aligned}
& d_{4,3}=\frac{e^{4 \cdot \mu+4^{2} \cdot \frac{\sigma^{2}}{2}}}{e^{3 \cdot \mu+3^{2} \cdot \frac{\sigma^{2}}{2}}}=e^{\mu+\frac{7 \cdot \sigma^{2}}{2}} \\
& d_{3,2}=\frac{e^{3 \cdot \mu+3^{2} \cdot \frac{\sigma^{2}}{2}}}{e^{2 \cdot \mu+2^{2} \cdot \frac{\sigma^{2}}{2}}}=e^{\mu+\frac{5 \cdot \sigma^{2}}{2}}
\end{aligned}
$$


$\mu$ and $\sigma$ are obtained:

$$
\sigma=\sqrt{\ln \left(\frac{d_{4,3}}{d_{3,2}}\right)} ; \mu=\ln \left(d_{3,2}\right)-\frac{5 \cdot \sigma^{2}}{2}
$$

Knowing $V,[C M], \rho_{\mathrm{wpa}}(\infty)$ and $\rho_{\mathrm{wp}}(\infty)$, the numbers of particles $N_{\mathrm{cm}}, N_{\mathrm{wpa}}$ and $N_{\mathrm{wp}}$ are computed as follows.

$N_{\text {wpa }}$ is determined using the measured fractal dimension:

$$
N_{\mathrm{wpa}}=\left\lceil\frac{\rho_{\mathrm{wpa}}(\infty)}{m_{\mathrm{wpa}}} \times V\right\rceil \text { with } m_{\mathrm{wpa}}=m_{\mathrm{wp}} \times\left(\frac{s_{\mathrm{wpa}}}{s_{\mathrm{wp}}}\right)^{D_{\mathrm{wpa}}}
$$

The number of native whey proteins, and casein micelles are computed in a similar way:

$$
N_{\mathrm{wp}}=\left\lceil\frac{\rho_{\mathrm{wp}}(\infty)}{m_{\mathrm{wp}}} \times V\right\rceil ; N_{\mathrm{cm}}=\left\lceil\frac{\rho_{\mathrm{cm}}}{m_{\mathrm{cm}}} \times V\right\rceil
$$

Starting from a random fat droplet space distribution with an empty interface, the model consists in fixing elements from the solution to a randomly selected location on the interface. This loop proceeds as follows:

- A fat droplet $d$ is chosen according to a random law: the probability is proportional to the droplet total surface.

- For coalescence, instead of simulating a population of fat droplets that are progressively merged, the droplets are supposed to be made of several sub-droplets of radius $r_{\text {sub }}$. Each droplet generated by the random space distribution corresponds to a set of sub-droplets of radius $r_{\text {sub }}$ with same cumulated volume. The radius follows an inverse power law $r_{\mathrm{sub}}^{d}(t)=r_{0}+\left(r^{d}-r_{0}\right) \cdot e^{-t}$. The surface is given by $s^{d}(t)=N_{\text {sub }}^{d}(t) \times 4 \pi\left(r_{\text {sub }}^{d}(t)\right)^{2}$ with $N_{\text {sub }}^{d}(t)=3 \times v^{d} \times\left[4 \pi\left(r_{\text {sub }}^{d}(t)\right)^{3}\right]^{-1}$ the mean number of sub droplets. Coalescence is considered as uniform for all droplets.

$t$ is initialised to 0 , and increased by an increment $\Delta t$ at each iteration:

$$
\frac{1}{\Delta t}=\left(F_{\mathrm{cm}} \times N_{\mathrm{cm}}+F_{\mathrm{wpa}} \times N_{\mathrm{wpa}}\right) \times\left(\sum_{d} s^{d}(t)\right)+F_{\mathrm{wp}} \times N_{\mathrm{wp}} \times\left[\sum_{d}\left(s^{d}(t)-s_{\mathrm{occ}}^{d}\right)\right]
$$

- If the WPs cover the whole available surface of the fat droplet (equivalent to $\Gamma>\Gamma_{\mathrm{wp}}=3.2 \mathrm{mg} \cdot \mathrm{m}^{-2}$ ), no other particle can be adsorbed. Another droplet is chosen.

- The choice of a type of particle is governed by a random law where the probability to choose an element is proportional to the affinity parameter of each type $\left(F_{\mathrm{cm}}, F_{\mathrm{wpa}}\right.$ and $\left.F_{\mathrm{wp}}\right)$.

$$
\text { For each } S \in\{\mathrm{cm}, \text { wpa, wp }\}: \operatorname{proba}_{S}=\frac{N_{S} \times F_{S}}{\sum_{U \in\{\mathrm{cm}, \mathrm{wpa}, \mathrm{wp}\}} N_{U} \times F_{U}}
$$

The position of the particle on the fat droplet surface is fixed as follows:

- If the particle is a WPA or a CM (including CMWP): its position on the surface is randomly chosen. If there is no collision with elements of the list of already fixed particles, the particle is added to the list attached to the fat droplet. The collision test is a geometrical computation based on the position and radius (after spreading) of each particle of the list. 
- If the particle is a native WP: the collision test is equivalently replaced by a Bernoulli process, whose parameter is the ratio between the available surface and the total surface of the droplet.

The previous loop ends when a maximum number of unsuccessful trials (i.e. without fixed element) is reached, or when all fat droplets are saturated.

The flow diagram of the $M 2 a$ algorithm is presented Figure 4

\subsubsection{Bridging between fat droplets $(M 2 b)$}

The estimation of the links is based on a stochastic process that considers each element capable of binding two droplets (i.e. whey protein aggregates and activated casein micelles CMWP). Casein micelles are considered to be activated (i.e. CMWP) as soon as they have fixed enough whey proteins on their surfaces. Model M1 gives an average mass of denatured whey proteins associated with casein micelles. The model introduces a normal distribution of the average mass of WP associated with a CM in order to avoid a threshold effect between (CM) and (CMWP) states:

$$
\frac{\rho_{\mathrm{cm}}(\infty) \times V}{N_{\mathrm{cm}}}
$$

Using the dispersion factor $\gamma_{\mathrm{cmwp}}$, it is possible to estimate how many CM's have more than $\mu_{\mathrm{cmwp}} \times m_{\mathrm{CM}}$ associated WP and become activated.

For each linkable particle of radius $r$ already adsorbed by a droplet, the following steps are performed:

- all droplets able to bind with the considered particle are sorted from the nearest to the farthest,

- for each droplet of this list, a random number $x$ is chosen in $\left(0, \mathrm{~K}_{\mathrm{LINK}} \times r\right)$. If the distance from the fat droplet to the considered particle is less than $x$, a link is created.

\subsubsection{Outputs of the model}

The model allows the calculation of three outputs:

- $\Gamma$, the interfacial concentration, given by the total mass of adsorbed particles including the associated WP divided by the total surface of all fat droplets.

- $w_{\mathrm{cm} \text { ads }}$, the ratio between the adsorbed caseins and the total amount of adsorbed proteins.

- $\mathrm{G}_{\text {link }}$, the average number of links by droplet.

\section{Results}

This section presents simulations for the model $\mathrm{M}$ with tests on an experimental data set. A threshold phenomenon has been observed in the [20\%,30\%] range of $w_{\mathrm{cm}_{0}}$ [27, 15]: There actually exists a complex balance between competitive reactions occurring in thermal treatment and complex dynamics of colonisation at the fat droplet interface during homogenisation. Understanding this behaviour is an open question.

A sensitivity analysis has been first performed, then a parameter optimisation has been run for estimating the optimal parameters of $\mathrm{M}$. If quantitative experimental data are available on interfacial concentration and casein mass ratio at interface, data about numbers of links between particles are not available. This is why sensitivity analysis and parameter optimisation have not been performed for the parameters and outputs of M2b. Nevertheless it has been shown that the number of links is directly related to rheological properties measured during the experiments [28]. 
Initialisation: empty distribution of fat droplets and numbers of adsorbable element equal to $\mathrm{Ncm}$ Nag Nwp

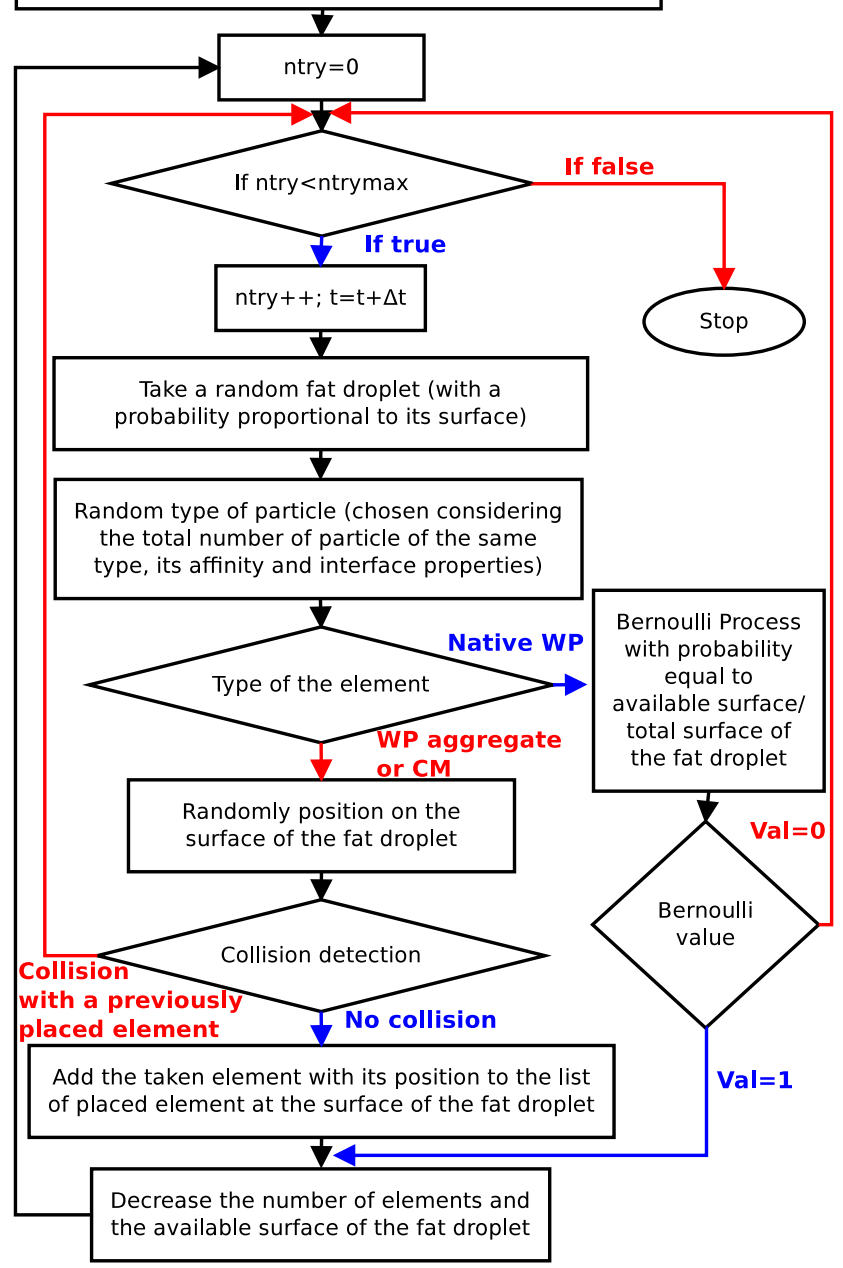

Figure 4: Flow diagram of the algorithm for the adsorption part of the stochastic model (M2a) 
Two parameters out of 9 of the models M1 and M2a are fixed: $r_{0}$, the radius of a fat droplet at the homogeniser exit, is set to $100 \mathrm{~nm}$, in concordance with the experimental observations. $\Gamma_{\mathrm{wp}}$ is fixed to 3.2 $\mathrm{mg} \cdot \mathrm{m}^{-2}$, in accordance to the literature [29], for single layer colonisation.

The sensitivity analysis and the parameter optimisation are made on parameters of M1 and M2a only. A logarithmic scale is used for the multiplicative parameters (that are here $k_{\{\mathrm{cm}, \mathrm{ag}\}}$ for M1, and $F_{\{\mathrm{cm}, \mathrm{wp}, \text { wpa }}$ for M2). For the sensitivity analysis, these parameters are arbitrarily bounded between $e^{-7}$ and $e^{7}$ (approximatively 0.001 and 1000), but they are not limited during optimisation. The spreading parameters $\left(\mathrm{Ksp}_{\mathrm{cm}}\right.$, $\mathrm{Ksp}_{\mathrm{wp}}$ ) are bounded between 1 (no spreading) and 4 (the particle takes 16 times its initial surface, which is equivalent to an occupied surface of $100 \mathrm{~m}^{2} . \mathrm{g}^{-} 1$ for a WPA and $150 \mathrm{~m}^{2} \cdot \mathrm{g}^{-} 1$ for a $\mathrm{CM}$, to be compared to the values founded section 4.2.1p.

Four inputs have been considered for the sensitivity analysis: $w_{\mathrm{cm}}$ (between $0 \%$ and $\left.100 \%\right), c_{\text {prot }}$ (between $40 \mathrm{~g} . \mathrm{L}^{-1}$ and $60 \mathrm{~g} . \mathrm{L}^{-1}$ in the given experimental conditions), $d_{3.2}$ (between 0.5 and $1 \mu \mathrm{m}$ ) and $\left(d_{4.3}-d_{3.2}\right)$ (between 0 and $0.5 \mu \mathrm{m}$ ).

Sensitivity analysis and parameter optimisation take as outputs the interfacial concentration and the casein mass percentage.

\subsection{Sensitivity analysis}

\subsubsection{Methodology}

The model is assimilated to a stochastic function $f: I \times \Omega \rightarrow O$ with:

- $I=(P \times U) \subset \mathbb{R}^{11}$ the inputs, that include model parameters and initial conditions (i.e. $k_{\{\mathrm{cm}, \mathrm{ag}\}}$, $F_{\{\mathrm{cm}, \mathrm{wp}, \mathrm{wpa}\}}, \mathrm{Ksp}_{\{\mathrm{cm}, \mathrm{wp}\}}$ and initial conditions $c_{\mathrm{prot}}, w_{\mathrm{cm}}, d_{3.2}$ and $\left.\left(d_{4.3}-d_{3.2}\right)\right) ; I$ is bounded by $\left(X_{\min }, X_{\max }\right) \in$ $\left(\mathbb{R}^{11}\right)^{2}$,

- $\Omega$ the sample space of the random generator of the model,

- $O \subset \mathbb{R}^{2}$ the output space for the model.

$|P|=50$ reference points have been chosen using a random Latin hypercube distribution in the space $I$. A stochastic exploration is then performed for each reference point and for each dimension of I. A squared uniform random law is used. 60 points are tested, so as we get $60 \times 11$ simulations for each reference point. As a whole, we get $60 \times 11 \times 50$ simulations.

The chosen perturbation is $x_{i}^{p}=x_{i}+2 \times r^{2} \times\left(X_{\max }^{i}-X_{\text {min }}^{i}\right)$, with $x_{i}^{p}$ a perturbation on $x_{i}$ and $r$ a random number in $[-1 ; 1]$.

The median of 8 repetitions for each output is considered in the sensitivity analysis. The data are then analysed using a three order polynomial least square regression. Each polynomial allows to evaluate one of the partial derivatives:

$$
\frac{\partial y_{j}}{\partial x_{i}}
$$

From the points of the latin square, three subsets $S$ are considered: $w_{\mathrm{cm}_{0}}<30 \%, 30 \%<w_{\mathrm{cm}_{0}}<60 \%$, $w_{\mathrm{cm}_{0}}>60 \%$.

Dependence $d_{i, j}(S)$ between input $i$ and output $j$ is evaluated by the sum of the partial derivatives on each subset $S$ :

$$
d_{i, j}(S)=\left(\sum_{(x, y) \in S} \frac{\partial y_{j}}{\partial x_{i}}\right) \times\left(\sum_{i} \sum_{(x, y) \in S} \frac{\partial y_{j}}{\partial x_{i}}\right)^{-1}
$$


4.1.2. Results of the sensitivity analysis

\begin{tabular}{|l|c|c|c|c|c|c|}
\hline $\mathrm{X}$ & \multicolumn{2}{|c|}{$w_{\mathrm{cm}_{0}}<30 \%$} & \multicolumn{2}{c|}{$30 \%<w_{\mathrm{cm}_{0}}<60 \%$} & \multicolumn{2}{c|}{$w_{\mathrm{cm}_{0}}>60 \%$} \\
\hline Parameter & $w_{\mathrm{cm}_{\mathrm{ads}}}$ & $\Gamma$ & $w_{\mathrm{cm}_{\mathrm{ads}}}$ & $\Gamma$ & $w_{\mathrm{cm}_{\mathrm{ads}}}$ & $\Gamma$ \\
\hline$k_{\mathrm{ag}}$ & ++ & +++ & + & & + & \\
\hline$k_{\mathrm{cm}}$ & +++ & ++++ & ++ & + & ++ & + \\
\hline $\mathrm{F}_{\mathrm{cm}}$ & +++ & ++ & +++ & + & ++ & + \\
\hline $\mathrm{F}_{\mathrm{wp}}$ & ++ & ++ & ++++ & ++ & ++ & + \\
\hline $\mathrm{F}_{\mathrm{wpa}}$ & ++ & & + & & & \\
\hline $\mathrm{Ksp}_{\mathrm{cm}}$ & ++ & +++ & ++ & +++++ & +++++ & +++++ \\
\hline $\mathrm{Ksp}_{\mathrm{wpa}}$ & +++ & +++ & ++++ & ++ & ++++ & ++ \\
\hline
\end{tabular}

Table 4: Impact of each parameter on each output of $\mathrm{M} 2 \mathrm{a}$, expressed as a percentage of the total perturbation: ()$<5 \%$, $(+)<10 \%$, $(++)<15 \%,(+++)<20 \%,(++++)<30 \%,(+++++)>30 \%$

The sensitivity analysis have been performed on the computer grid MIGALE of the INRA Jouy-en-Josas. It has taken 3 days using 100 parallel jobs.

Table 4 presents the influence of parameters on the model response. M1 has a stronger influence when the initial concentration of caseins is low. This is due to the high concentration of native WPs that could be denatured in this case. $\mathrm{F}_{\mathrm{cm}}$ and $\mathrm{F}_{\mathrm{wp}}$ have more impact on $w_{\mathrm{cm}}$ ads when $30 \%<w_{\mathrm{cm}_{0}}<60 \%$. The impact of $F_{\text {wpa }}$ is more important when $w_{\mathrm{cm}_{0}}<30 \%$, but remains quite low. A possible reason could be due to the boundaries chosen for M1 parameters, that could disadvantage WPA formation. $\mathrm{Ksp}_{\mathrm{cm}}$ and $\mathrm{Ksp}_{\mathrm{wpa}}$ are key parameters for the model. They have a strong impact on both $\Gamma$ and $w_{\mathrm{cm}_{\mathrm{ads}}}$.

\subsection{Identification of parameters by optimisation}

\subsubsection{Evolutionary optimisation}

The problem of identifying an optimal parameter setting for a model according to an experimental dataset is a complex optimisation problem. The coupled model presented above has an obviously non linear and stochastic behaviour, this is a reason why a robust stochastic optimisation has been used. The algorithm used in this section is an Evolutionary Algorithm (EA), which corresponds to a large set of techniques that rely on the computer simulation of natural evolution mechanisms (Artificial Darwinism) [30, 31, 32, 33, 34].

EAs copy natural evolution with very simple stochastic operators. According to Darwin [35], adaptation is based on three mechanisms: random variations, inheritance, and survival / reproduction of the fittest individuals. Used for computational optimisation, this scheme has the major advantage to make only few assumptions on the function to be optimised (there is no need to have a continuous or derivable function for instance). In short, Evolutionary Algorithms consider a population of potential solutions exactly as a population of individuals of a natural population that live, fight and reproduce. The environment pressure is replaced by an "optimisation" pressure: the function to be optimised, the fitness, is considered as a measure of the adaptation of the individual to its environment (fitness). In this way, individuals that reproduce are the best ones with respect to the problem to be solved.

\subsubsection{Search space and fitness function}

The parameter estimation is turned into an optimisation problem as follows: the optimal parameter set is searched in the space of all possible parameter sets. The function to be optimised, the fitness function, is an estimation of the quality of the model: a least square fitting of the predicted values (interfacial concentration and mass percentage of caseins at interface) on the learning sample (Database 1). As the model is stochastic, 


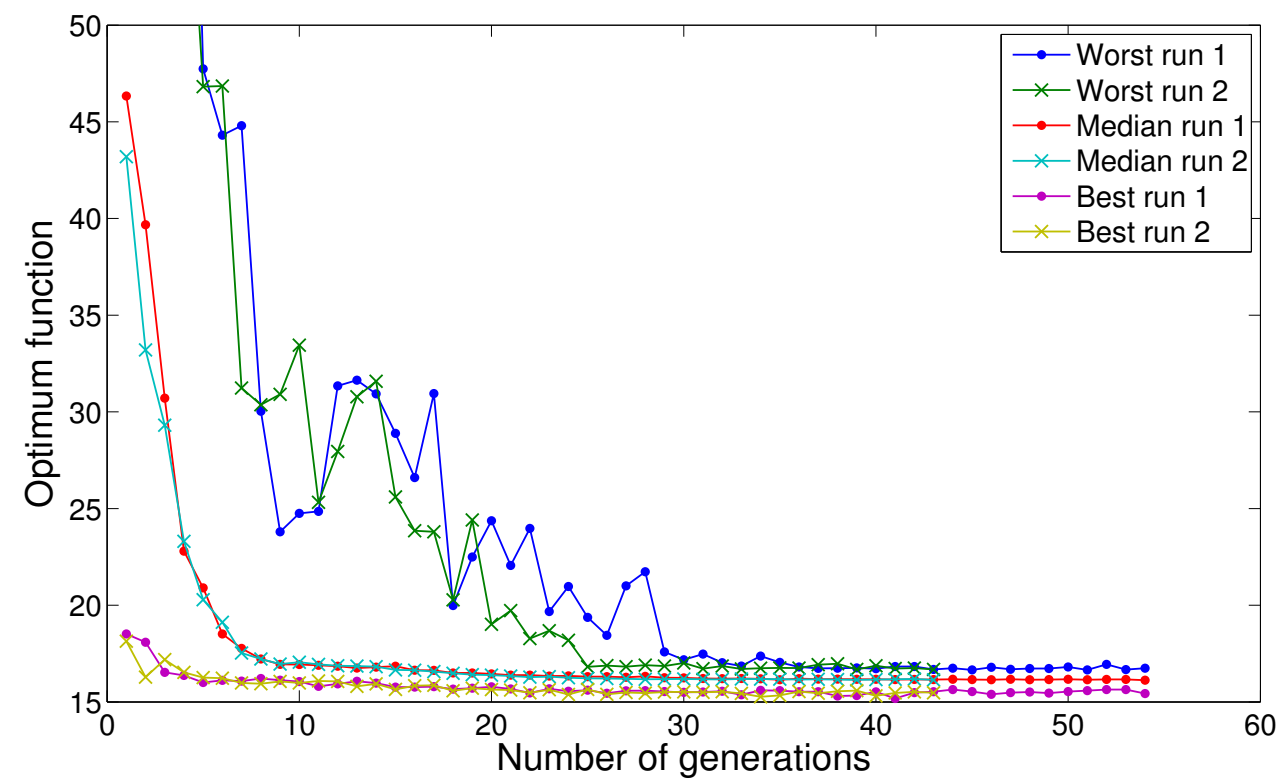

Figure 5: Fitness value during optimisation

it is run 12 times on each of the 7 points of the experimental data set (Database 1). The median of each experimental point is used for the fitness computation:

$$
\text { fitness }=\sum_{i}\left|y_{i}-z_{i}\right|^{2}
$$

with :

- $S=\left(x_{i}, y_{i}\right)_{i=1}^{7} \subset U \times O$ the data set (Database 1).

- $z_{i}=\operatorname{median}_{j} M\left(\left(p, x_{i}\right), s_{j}\right)$ the estimation of each point by simulating model $M$.

\subsubsection{Algorithm}

The Covariance Matrix Adaptation Evolution Strategy (CMA-ES) [14] has been used. CMA-ES is considered as one of the best real-value optimizers for single-objective problems, delivering high-quality results in a very limited amount of time. Its population size was set to $\lambda=256$, and log scale weights have been used for the update of $\mu$ (the number of offspring's generated at each generation). Search was initialised at the following point: $\left(k_{\mathrm{cm}}=1 \mathrm{~m}^{1.5} \cdot \mathrm{g}^{-0.5}, k_{\mathrm{ag}}=1, F_{\mathrm{cm}}=1, F_{\mathrm{wp}}=1, F_{\mathrm{wpa}}=1, \mathrm{Ksp}_{\mathrm{cm}}=2, \mathrm{Ksp}_{\mathrm{wpa}}=2\right)$

During model development, non-linear optimisation methods have been tested (including CMA-ES, NSGA-2 and Monte-Carlo random search), and it appeared that CMA-ES converged faster than the others to one of the best fitting parameter sets. Due to the heavy computationnal nature of the model (depending to the parameters it takes from 20 min to 5 hours to evaluate one set of parameters on a recent core), only two run of CMA-ES have been made for the last revision of the model.

Figure 5 shows the fitness evolution of the two run of CMA-ES that have been made with the latest revision of the model. The longest run have taken 3 days and 7 hours on a computational server of 64 
cores (with $8 \mathrm{Xeon}(\mathrm{R}) \mathrm{CPU}$ E7- 8837 processor at $2.67 \mathrm{GHz}$ of 8 core) to make 54 generations. Due to heavy computational issues the program have been written using $\mathrm{C}++$ and Fortran program languages. The CMA-ES implementation used is from [14].

The best global fitness has been found for: $k_{\mathrm{cm}}=4.66 \mathrm{~m}^{1.5} \mathrm{~g}, k_{\mathrm{ag}}=7.6 \cdot 10^{-3}, F_{\mathrm{cm}}=0.13, F_{\mathrm{wp}}=7.0 \cdot 10^{-4}$, $F_{\text {wpa }}=0.16, \mathrm{Ksp}_{\mathrm{cm}}=1.64$ and $\mathrm{Ksp}_{\mathrm{wpa}}=2.14$.

- The difference of magnitude between $k_{\mathrm{cm}}$ and $k_{\mathrm{ag}}$ is due to their units (Table 2). It is then difficult to make a comparison between these reactions.

- $F_{\text {wp }}$ is lower than the other F. Recall the probability to choose one particle (CMs, WPAs, WPs) is proportional to the product of their number and the corresponding F coefficients (equation 12 ). The small value of $F_{\mathrm{wp}}$, is compensated by the large number of WP.

- Surface occupied by CMs and WPAs are computed using the spreading parameters $\mathrm{Ksp}_{\mathrm{cm}}$ and $\mathrm{Ksp}_{\mathrm{wpa}}$. These values can be compared to the spreading of native WPS calculated from litterature data ( [36],[29]): around $\sqrt{\frac{1500}{312}}=2.19$. Organized structures like casein micelles or whey protein aggregates have been shown to spread in a less extent than native whey proteins.

- Using the identified spreading parameters, the specific occupied surface are equivalent to $26 \mathrm{~m}^{2} \cdot \mathrm{g}^{-1}$ and $29 \mathrm{~m}^{2} \cdot \mathrm{g}^{-1}$ for the CMs and WPAs respectively. The maximum surface occupied by a single layer of native WPs is fixed in the model to $312 \mathrm{~m}^{2} \cdot \mathrm{g}^{-1}$ [29]. The calculated parameters are compared to data measured during the experiments on a Langmuir balance. Surface areas occupied by $1 \mathrm{~g}$ of the various protein species were estimated in real emulsion systems produced with pure proteins. The apparent surface area occupied by $1 \mathrm{~g}$ of the different protein species was estimated by the specific surface of the emulsion (6/D32) divided by the protein load at the interface of droplets measured according to the method described by Patton and Huston [17]. It was done for solutions of casein micelles and whey proteins near the ratios manipulated in this paper and for a same mean fat droplet size but at an air in water interface. It gives an order of magnitude for a target of behavior, even if it cannot be used for a quantitative validation. The values found for $s_{w p}$ and $s_{c m}$ were equal respectively to $473 \mathrm{~m}^{2} / \mathrm{g}$ and 98 $\mathrm{m}^{2} / \mathrm{g}$, which is in accordance with the order of magnitude of the parameters we found.

\subsection{Validation of the model}

The stochasticity of the model is presented in Figure 6 The variability induced by this stochasticity is obviously higher for the interfacial concentration than for the casein percentage at interface.

The variability of the interfacial concentration is particularly high for initial percentage of caseins between 20 and $50 \%$. It is in this range that the competition between particle is the highest and can mostly impact the amount of available surface on the fat droplets. This might be enhanced by the fact that, according to table 1 the difference between $d_{4.3}$ and $d_{3.2}$ is higher in this case. This induces a more dispersed distribution of droplet sizes.

The percentage of casein at interface is less impacted by the stochasticity of the model than the interfacial concentration.

Figure 7 and Table 4.3 show the behaviour of the model fitting to experimental data. Generally, the model has a good fit for the two outputs of the system and for the two databases tested (Database 1 for the parameter estimation and Database 2 for the test). A mean error is calculated :

- For the output $w_{\mathrm{cm}_{\mathrm{ads}}}: 9.3 \%$ and $7.3 \%$ respectively for Database 1 and Database 2 

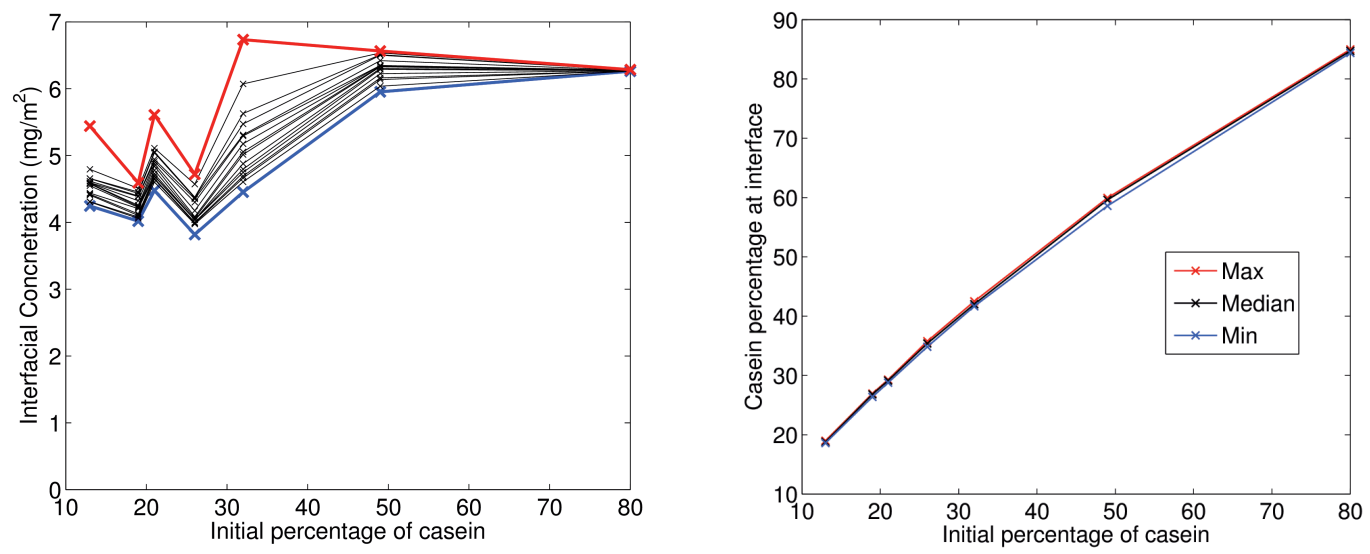

Figure 6: Model behaviour of 16 different runs that point out the stochasticity of the model

- For the output $\Gamma$ : $12.5 \%$ and $15.3 \%$ respectively for Database 1 and Database 2 of the maximal experimental value.

This is comparable to the experimental measurement error of $10 \%$. However two points on the first Database 1 are not well predicted: one for an interfacial concentration at $21 \%$ of initial casein rate and the other for the percentage of casein at $32 \%$ of initial casein rate. Moreover, a weakness of the model for low values of $w_{\mathrm{cm}_{0}}$ is observed. It might be due to a change of behaviour at the interface. This lack of fit reflects the complexity of the interfacial organisation. The data set shows a complex balance between competitive reactions occurring in thermal treatment and complex dynamics of colonisation at the fat droplet interface during homogenisation [1].

An example of prediction of the spatial structure of the gel by M2b is presented Figure 8 It is reached for a non fitted set of parameters $\left(K_{\text {link }_{\max }}=5, \mu_{\mathrm{cmwp}}=0.6\right)$. It seems qualitatively coherent with the sensory measurements achieved during the experiments [27, 15]. Indeed we know that the number of links is directly related to rheological properties $([\overline{28}])$. As a consequence, it seems possible to have an indirect measurement of sensory characteristics through an evaluation of the number and the nature (WPA or CMWP connection) of created links.

For low values of $w_{\mathrm{cm}_{0}}$, (Figure $8 \mathrm{l}$ ) solutions were evaluated as firm gelified structures. It is correlated with the number of links predicted by the model (here 842). Same results are observed for $w_{\mathrm{cm}_{0}}=49 \%$ (Figure 8p), with two kinds of links: one created by CMWPs (here 859) and another by WPAs (here 244). The type of links involved in the structure has probably an impact on the texture. Nevertheless, it can not be depicted using a global sensory analysis. For $w_{\mathrm{cm}_{0}}=80 \%$ (Figure 8 ), the structure appears completely different, with a number of links radically reduced. It is coherent with liquid perception of the gel for this initial ratio.

\section{Discussion}

The model is able to fit relatively well the experimental data except for some of the points in Figure 7 In order to improve the results several ideas can be considered: 


\section{Database 1}
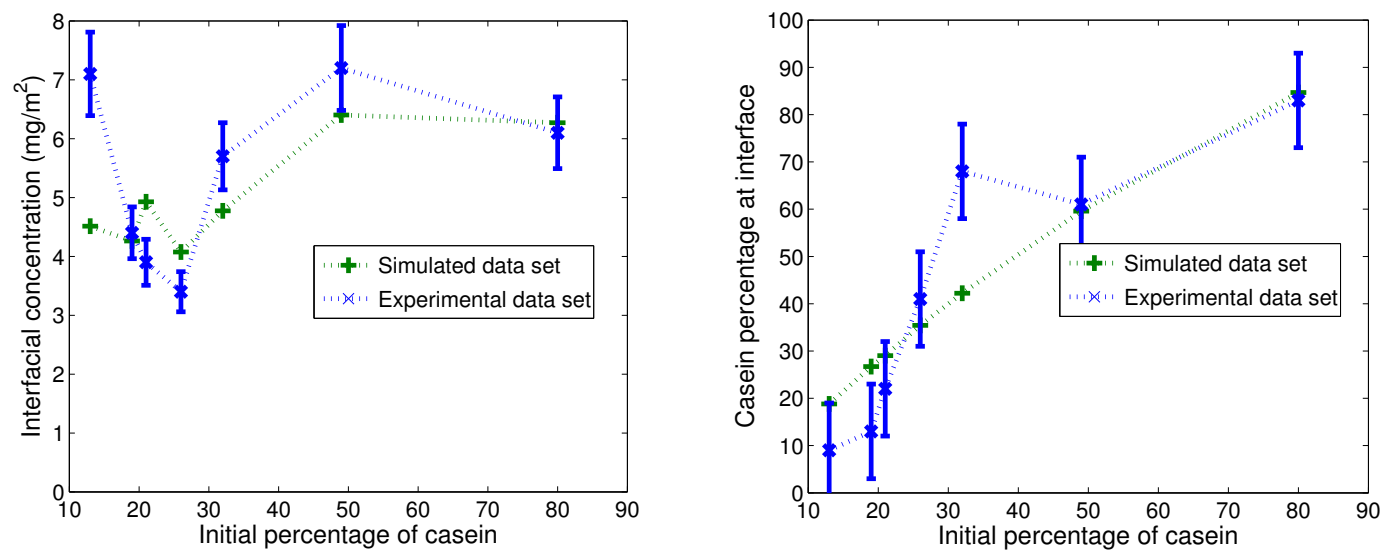

\section{Database 2}
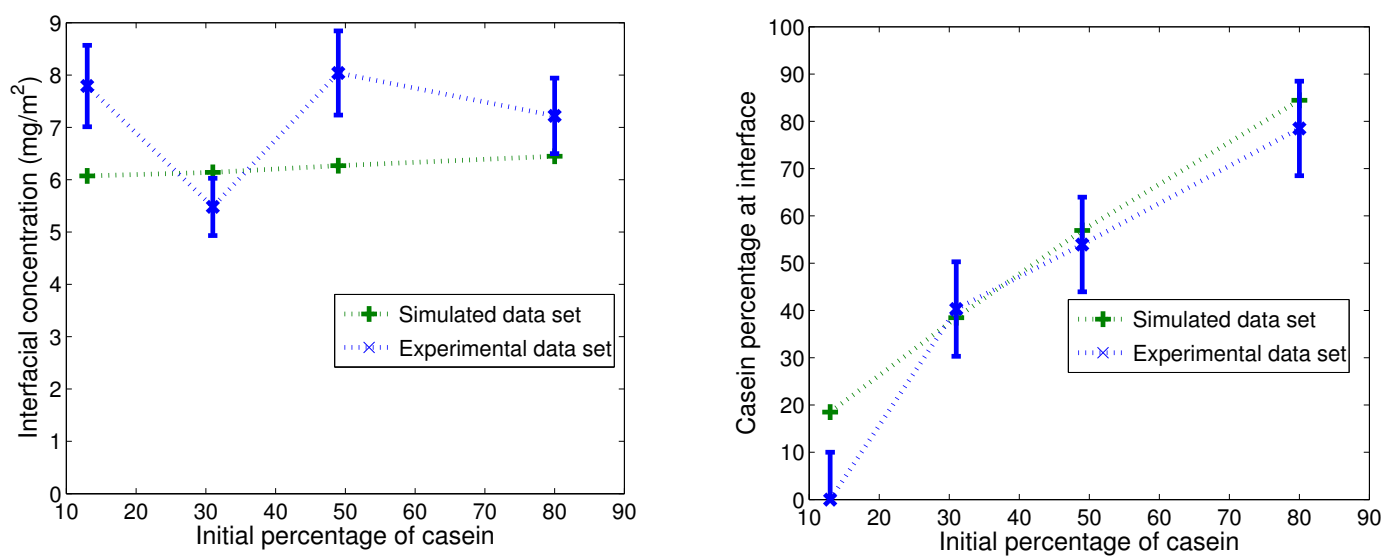

Figure 7: Comparison between experimental data (from Databases 1 and 2) with the model behaviour when using the best parameter set 


\begin{tabular}{|l|l|l|l|}
\hline $\begin{array}{l}\text { Experimentals } \\
\text { results }\end{array}$ \\
$\begin{array}{l}\text { At } 13 \% \text { of initial } \\
\text { cercentage } \\
\text { experiments give a } \\
\text { gelified structure }\end{array}$ \\
\hline (a)
\end{tabular}




\begin{tabular}{|c|c|c|c|c|}
\hline$w_{\mathrm{cm}_{0}}$ & \multicolumn{2}{|c|}{$w_{\mathrm{cm}_{\mathrm{ads}}}$} & \multicolumn{2}{c|}{$\Gamma$} \\
\hline exp & exp & model & exp & model \\
\hline$\%$ & $\%$ & $\%$ & mg.m ${ }^{-2}$ & mg.m ${ }^{-2}$ \\
\hline \hline \multicolumn{5}{|c|}{ Database 1 } \\
\hline \hline 13 & 9 & 18 & 7.10 & 4.63 \\
\hline 19 & 13 & 26 & 4.40 & 4.29 \\
\hline 21 & 22 & 29 & 3.90 & 4.94 \\
\hline 26 & 41 & 35 & 3.40 & 4.07 \\
\hline 32 & 68 & 41 & 5.70 & 5.15 \\
\hline 49 & 61 & 59 & 7.20 & 6.35 \\
\hline 80 & 83 & 84 & 6.10 & 6.27 \\
\hline \hline \multicolumn{5}{|c|}{ Database 2} \\
\hline \hline 13 & 0 & 18 & 7.79 & 6.06 \\
\hline 31 & 40 & 38 & 5.48 & 6.15 \\
\hline 49 & 53 & 56 & 8.04 & 6.25 \\
\hline 80 & 78 & 84 & 7.22 & 6.44 \\
\hline
\end{tabular}

Table 5: Model evaluation using the best fitted parameter of M1 and M2a.

- The organisation of the interface is currently assumed to be in a single layer. In reality it has been suggested that the interface might be more complex when several types of particles are in competition [1]. Nevertheless few quantitative knowledge is available.

- The stochastic representation of the competition between casein micelles and whey protein aggregates could be improved by adding knowledge on the colonisation phenomena.

- Another further development could be a model that simulates the coalescence between fat droplets as a stochastic process instead of the mean field approach.

Nevertheless the above improvements would increase the computation complexity of the model which is already high. The adequate model complexity is a question of balance between the computation burden and the physical reality.

\section{Conclusion and future work}

This combination of a deterministic and a stochastic model shows relevant results in replicating the behaviour of the complex artificial concentrated milk protein mix under study. Such a model can help us to have a better understanding of the system through simulation analysis. Further studies will be done along the directions described in the previous section.

\section{Acknowledgements}

The research leading to these results has received funding from the European Community's Seventh Framework Programme (FP7/2007-2013) under the grant agreement FP7-222 654-DREAM. 
The authors would like to thank Claire Surel, Marc Anton from INRA BIA Nantes, and Marine Rouland from IFR Norwich, for their precious help in building of the model and providing experiments. Computational resources have been provided by ISC-PIF and INRA-Jouy-en-Josas (MIGALE grid).

[1] E. Dickinson, Milk protein interfacial layers and the relationship to emulsion stability and rheology, Colloids and surfaces B - biointerfaces 20 (3) (2001) 197-210.

[2] D. McClements, Protein-stabilized emulsions, Current opinion in colloid \& interface science 9 (5) (2004) 305-313.

[3] E. Dickinson, Caseins in emulsions: interfacial properties and interactions, International Dairy Journal 9 (3-6) (1999) 305-312, 1997 Hannah Symposium on Caseins and Caseinates - Structures, Interactions, Networks, HANNAH RES INST, AYR, SCOTLAND, MAY 21-23, 1997. doi:10.1016/ S0958-6946(99)00079-5.

[4] F. Guyomarc'h, A. Law, D. Dalgleish, Formation of soluble and micelle-bound protein aggregates in heated milk, Journal of Agricultural and Food Chemistry 51 (16) (2003) 4652-4660.

[5] B. Murray, Interfacial rheology of food emulsifiers and proteins, Current opinion in colloid \& interface science 7 (5-6) (2002) 426-431. doi : 10.1016/S1359-0294(02)00077-8.

[6] Z. Gaygadzhiev, A. Hill, M. Corredig, Influence of the emulsion droplet type on the rheological characteristics and microstructure of rennet gels from reconstituted milk, Journal of Dairy Research 76 (3) (2009) 349-355. doi : 10.1017/S002202990900418X

[7] J. Knudsen, L. Ogendal, L. Skibsted, Droplet surface properties and rheology of concentrated oil in water emulsions stabilized by heat-modified beta-lactoglobulin B, Langmuir 24 (6) (2008) 2603-2610. doi: $10.1021 / \mathrm{la} 703810 \mathrm{~g}$

[8] E. Dickinson, Mixed biopolymers at interfaces: Competitive adsorption and multilayer structures, Food Hydrocolloids 25 (8) (2011) 1966-1983. doi: 10.1016/j . foodhyd.2010.12.001

[9] M. Rabe, D. Verdes, S. Seeger, Understanding protein adsorption phenomena at solid surfaces, Advances in Colloid and Interface Science 162 (1-2) (2011) 87-106.

[10] M. Morand, A. Dekkari, F. Guyomarc'h, M. Famelart, Increasing the hydrophobicity of the heatinduced whey protein complexes improves the acid gelation of skim milk, International Dairy Journal 25 (2) (2012) 103-111. doi: 10.1016/j.idairyj.2012.03.002.

[11] J. Foucquier, E. Chantoiseau, S. L. Feunteun, D. Flick, S. Gaucel, N. Perrot, Toward an integrated modeling of the dairy product transformations, a review of the existing mathematical models, Food Hydrocolloids 27 (1) (2012) 1-13. doi : 10.1016/j . foodhyd.2011.08.002. URL http://www.sciencedirect.com/science/article/pii/S0268005X11002268

[12] J. Feder, Random sequential adsorption, Journal of Theoretical Biology 87 (2) (1980) 237 - 254. doi: 10.1016/0022-5193(80)90358-6. URL http://www.sciencedirect.com/science/article/pii/0022519380903586

[13] A. Nasir, J. McGuire, Sequential and competitive adsorption of bovine serum albumin and $\beta$ lactoglobulin, and their resistance to exchange with $\alpha$-lactalbumin and $\beta$-casein Food Hydrocolloids 12 (1) (1998) 95 - 103. doi : 10.1016/S0268-005X(98)00050-2 URL http://www.sciencedirect.com/science/article/pii/S0268005X98000502 
[14] N. Hansen, A. Ostermeier, Completely derandomized self-adaptation in evolution strategies, Evolutionary computation 9 (2) (2001) 159-195.

[15] C. Surel, J. Foucquier, N. Perrot, A. Mackie, C. Garnier, A. Riaublanc, M. Anton, Composition and structure of interface impacts texture of o/w emulsions, paper in review (2012).

[16] R. M., Production and characterization of colloidal food model to provide data for modeling of dispersed systems, Training work, Institute of Food Research (IFR), Norwich.

[17] S. Patton, G. Huston, A method for isolation of milk-fat globules, Lipids 21 (2) (1986) 170-174.

[18] A. Markwell, S. Haas, L. Bieber, N. Tolbert, Modification of Lowry procedure to simplify protein determination in membrane and lipoprotein samples, Analytical Biochemistry 87 (1) (1978) 206-210.

[19] C. Curt, N. Perrot, L. Agioux, I. Allais, I. Ioannou, B. Edoura-Gaena, G. Trystram, J. Hossenlopp, Formalization of at-line human evaluations to monitor product changes during processing : the concept of sensory indicator, berlin Edition, S. Verlag, 2004.

[20] Tolkach, Alexander, Kulozik, Ulrich, Reaction kinetic pathway of reversible and irreversible thermal denaturation of $\beta$-lactoglobulin. Lait 87 (4-5) (2007) 301-315. doi : 10. 1051/lait: 2007012 URL http://dx.doi.org/10.1051/lait:2007012

[21] A. Tolkach, S. Steinle, U. Kulozik, Optimization of thermal pretreatment conditions for the separation of native $\alpha$-lactalbumin from whey protein concentrates by means of selective denaturation of $\beta$-lactoglobulin, Journal of food science 70 (9) (2006) E557-E566.

[22] E. Chantoiseau, A. Plana-Fattori, C. Doursat, D. Flick, Coupling fluid flow, heat transfer and thermal denaturation-aggregation of beta-lactoglobulin using an eulerian/lagrangian approach Journal of Food Engineering 113 (2) (2012) $234-244$. doi : 10.1016/j . jfoodeng. 2012.05.043 URL http://www.sciencedirect.com/science/article/pii/S0260877412002750

[23] E. Dickinson, Competitive adsorption and protein-surfactant interactions in oil-in-water emulsions, in: ACS Symp. Ser, Vol. 448, ACS Publications, 1991, pp. 114-129.

[24] J. Brun, D. Dalgleish, Some effects of heat on the competitive adsorption of caseins and whey proteins in oil-in-water emulsions, International Dairy Journal 9 (3-6) (1999) 323-327, 1997 Hannah Symposium on Caseins and Caseinates - Structures, Interactions, Networks, HANNAH RES INST, AYR, SCOTLAND, MAY 21-23, 1997. doi : 10.1016/S0958-6946(99)00082-5

[25] M. Verheul, S. Roefs, J. Mellema, K. de Kruif, Power law behavior of structural properties of protein gels, Langmuir 14 (9) (1998) 2263-2268.

[26] P. Aymard, D. Durand, T. Nicolai, The effect of temperature and ionic strength on the dimerisation of $\beta$-lactoglobulin, International journal of biological macromolecules 19 (3) (1996) 213-221.

[27] C. Surel, J. Foucquier, N. Perrot, A. Mackie, C. Garnier, A. Riaublanc, M. Anton, Heating milk proteins impact interface proteins adsorption and texture of emulsion : a way to innovative textures, in: Food Colloids, Copenhague (Danemark), 2012.

[28] E. Dickinson, Structure and rheology of simulated gels formed from aggregated colloidal particles, Journal of colloid and interface science 225 (1) (2000) 2-15. 
[29] J. A. Hunt, D. G. Dalgleish, Adsorption behaviour of whey protein isolate and caseinate in soya oil-inwater emulsions, Food Hydrocolloids 8 (2) (1994) 175-187.

[30] A. S. Fraser, Simulation of genetic systems by automatic digital computers. i. introduction, Aust J Biol Sci 10 (1957) 484-491.

[31] H.-J. Bremermann, Optimization through evolution and recombination, Self-Organizing Systems (1962) 93-106M.C. Yovits, G.T. Jacobi, and G.D. Goldstein (eds.), Spartan Books, Washington DC,.

[32] J. H. Holland, Outline for a logical theory of adaptative systems, Journal of the association for the Computing Machinery (3) (1962) 297-314.

[33] I. Rechenberg, Evolutionsstrategie : Optimierung Technicher System nach Prinzipien der Biologischen Evolution, Fromman Holzboog, Stuttgart, 1973.

[34] T. Bäck, H.-P. Schwefel, An overview of evolutionary algorithms for parameter optimization, Evolutionary computation 1 (1) (1993) 1-23.

[35] C. Darwin, $n$ the Origin of Species by Means of Natural Selection, or the Preservation of Favoured Races in the Struggle for Life, John Murray, 1859. URL http://darwin-online.org.uk

[36] D. G. Dalgleish, Adsorption of protein and the stability of emulsions, Trends in Food Science and Technology 8 (1) (1997) 1 - 6. doi:10.1016/S0924-2244(97)01001-7 URL http://www.sciencedirect.com/science/article/pii/S0924224497010017 